\title{
Effects of Moisture in the Air on Characteristics of Strength in High Strength Spheroidal Graphite Cast Iron*1
}

\author{
Naoto Shiraki and Kazuyuki Morita*2 \\ Faculty of Engineering, Tokyo City University, Tokyo 158-8557, Japan
}

The purpose of this study is to investigate the effects of humidity on the strength characteristics in high strength spheroidal graphite cast iron with two phases, which is ferrite and pearlite. Three spheroidal graphite cast irons (FCD400(FDI), FCD500(FPDI.82) and FCD600(FPDI.55)) were used as specimens. In addition, heat treatment (Normalizing) was conducted in FCD500 (PDI). Tensile test conforming to JIS was carried out using these resultant four materials in air and water. The specimen used was of the 14A type. The relationship between tensile strength and area ratio of brittle fracture was investigated. Fatigue crack propagation test conforming to ASTM was also carried out using these materials. Stress ratio $R$ was 0.1 , and the specimen used was of the 1CT type with a thickness of $12.5 \mathrm{~mm}$. The test was carried out at room temperature and three kinds of humidity: 0,40 and $80 \%$. The relationship between the characteristics of fatigue crack propagation and crack closure generated on the fracture surface was investigated.

Though tensile strength in FDI and FPDI.82 was not influenced by water brittlement, strength in PDI and FPDI.55, which included pearlite, was decreased by water brittlement. This phenomenon may mainly be caused by the amount of parlite in the matrix. The threshold stress intensity factor range $\Delta K_{\text {th }}$ of all materials increased with increasing humidity. Crack closure was investigated in all materials. It seemed to become marked with increasing humidity. In the low $\Delta K_{\text {eff }}$ region of all materials (except FPDI.55, 80\%), the fatigue crack propagation rate was almost the same because of oxide-induced crack closure of the ferrite included in the matrix. In the high $\Delta K_{\text {eff }}$ region of FPDI and PDI, the rate was not the same. The acceleration was investigated because of effect of a phenomenon similar to the water embrittlement of pearlite included in the matrix. [doi:10.2320/matertrans.F-M2015812]

(Received December 24, 2014; Accepted May 11, 2015; Published July 25, 2015)

Keywords: spheroidal graphite cast iron, ferrite, pearlite, tensile test, fatigue crack propagation test, humidity, water embrittlement, threshold stress intensity factor range, effective stress intensity factor range, oxide-induced crack closure

\section{Introduction}

Spheroidal graphite cast iron has been widely used for automotive parts as well as for the parts of water supply and sewerage systems due to its superior mechanical characteristics. ${ }^{1)}$ However, to design these components for mechanical structures, which are subjected to cyclic loads, sufficient consideration needs to be given to fatigue failure. If cracks occur within the materials with the stress intensity factor range $\Delta K$ below the threshold stress intensity factor range $\Delta K_{\text {th }}$, then the fatigue cracks will cease to propagate. However, the fatigue crack propagation property, including $\Delta K_{\text {th }}$, are known to be sensitive to effects brought about by the test environment. ${ }^{2)}$

The matrix of spheroidal graphite cast iron generally comprises ferrite and pearlite, and its tensile strength can be varied through adjustment of the ratio of the matrix composition. Shibuya et al. reported that when a tensile test is conducted on wet spheroidal graphite cast iron with a pearlite matrix of high tensile strength, both the tensile strength and the elongation properties were significantly diminished; they called this the water embrittlement. ${ }^{3)}$ They also reported that surface treatment such as ferritization of surface layers might be effective as a method for suppressing effects brought about by this water embrittlement. ${ }^{4)}$ Additionally, Usami et al. reported that water affects not only the tensile strength, but also fatigue crack propagation properties, and that the degree to which these are affected varies depending on the matrix. They also reported that even

\footnotetext{
${ }^{* 1}$ This Paper was Originally Published in Japanese in J. JFS 85 (2013) 843 849 .

${ }^{* 2}$ Graduate Student, Tokyo City University
}

austempered spheroidal graphite cast iron made up of bainitic ferrite is also subjected to a phenomenon similar to water embrittlement. ${ }^{5)}$ In our previous work, we have also reported that the result of the fatigue crack propagation test using a two-phase spheroidal graphite cast iron comprised ferrite and bainitic ferrite demonstrated that a two-phase treatment was found to be effective in improving the fatigue crack propagation properties. $^{6}$ )

The findings described above suggest that atmospheric moisture may affect the fatigue crack propagation property of pearlite-containing spheroidal graphite cast iron, and that the ferrite phase may provide superior fatigue crack propagation resistance and may be able to reduce the effects of water embrittlement on pearlite matrices in spheroidal graphite cast iron containing both ferrite and pearlite. Therefore, in this study, we used spheroidal graphite cast iron samples with varying composition ratios to evaluate the effects brought about by atmospheric moisture focusing on both their tensile strength and fatigue crack propagation properties.

\section{Sample Materials}

The equivalents of FCD400, FCD500, and FCD600 spheroidal graphite cast irons with chemical compositions that are compliant with JIS G 55027) were used as the sample materials, as shown in Table 1. Additionally, a pearlite single-phase matrix was obtained by placing FCD500 in an atmospheric furnace at $1203 \mathrm{~K}$ for $10.8 \mathrm{ks}$ followed by aircooling as a normalizing treatment. Ferrite-to-pearlite composition ratio in microstructure, and graphite shape for each material are shown in Fig. 1. The FCD400 specimen had a ferrite single-phase structure, and both the FCD500 and FCD600 specimens comprised a ferrite phase around the 


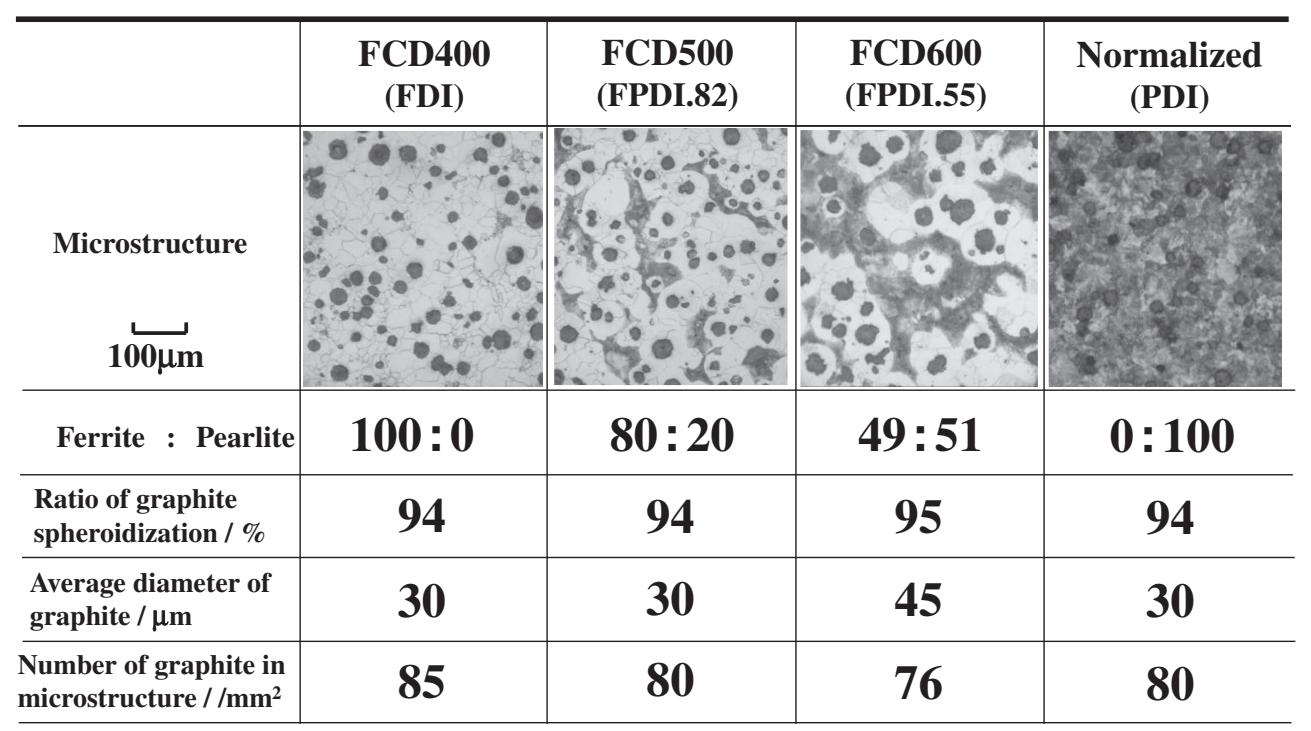

Fig. 1 Microstructures, area ratio of ferrite/pearlite and graphite shapes of four materials.

Table 1 Chemical composition of materials.

\begin{tabular}{ccccccc}
\hline Material & $\mathrm{C}$ & $\mathrm{Si}$ & $\mathrm{Mn}$ & $\mathrm{P}$ & $\mathrm{Mg}$ & $\mathrm{S}$ \\
\hline FCD400 & 3.60 & 3.00 & 0.40 & 0.15 & 0.06 & 0.02 \\
FCD500 & 3.60 & 2.60 & 0.45 & 0.15 & 0.06 & 0.02 \\
FCD600 & 3.61 & 2.30 & 0.51 & 0.02 & 0.06 & 0.02 \\
\hline
\end{tabular}

graphite and a bull's-eye structure with pearlite phase everywhere else. The heat-treated FCD500 specimen was comprised of a pearlite single-phase.

The ratio of the ferrite matrix $(\mathrm{F})$ to the pearlite matrix $(\mathrm{P})$ was $100: 0$ for the FCD400, $80: 20$ for FCD500, $49: 51$ for FCD600, and $0: 100$ for the (normalized) heat-treated material. Additionally, no differences were found in the graphite shape and distribution state among the materials. The names of the sample materials in this paper reflect the matrices ( $\mathrm{F}$ and $\mathrm{P}$ for ferrite and pearlite, respectively) and the composition ratio thereof, for example FDPI.82 (refer to Fig. 1).

\section{Experimental Procedure}

\subsection{Tensile test}

The tensile test was conducted using an Instron-type universal tester (made by Shimadzu Corp. Ltd.). The crosshead displacement rate was $0.5 \mathrm{~mm} / \mathrm{min}$, and tests were conducted in the atmospheric environment at room temperature as well as in the water environment. Additionally, the specimens used in this tensile test was a 14A type tensile specimens that were $8 \mathrm{~mm}$ in diameter for the parallel area and was compliant with JIS Z 2241. ${ }^{8)}$ The test was conducted using three specimens under each condition.

The test in the water environment was carried out by the following steps: degreasing the specimens with acetone; covering the parallel part of the specimen with a rubber hose; holding and fixing the bottom part in place with a hose retainer; and filling the hose with approximately $287 \mathrm{~K}$ tap
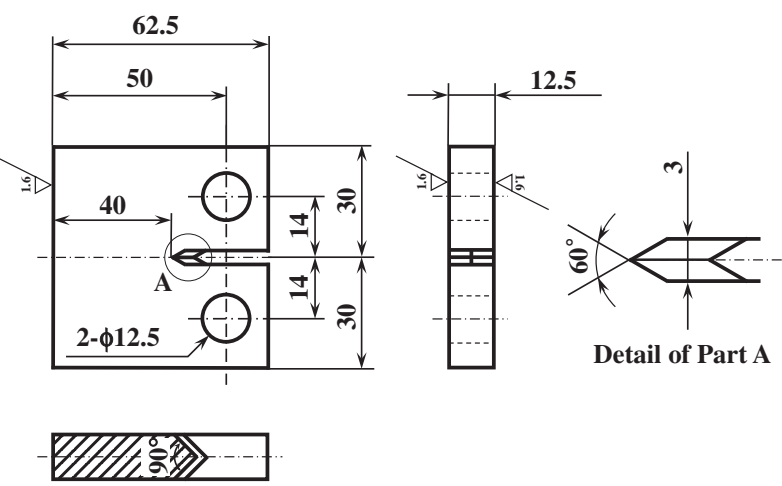

Fig. 2 Shape and dimension of CT specimen.

water. After the tensile test was completed, the fractured surface was observed using a scanning electron microscope (SEM). The pictures of all the specimen surfaces were taken at five locations at near-equal intervals after the fractures occurred. The calculations for the brittle/ductile fracture ratio were performed based on fractures found in 100 locations (nodes) by overlaying a $10 \mu \mathrm{m}$ mesh on the pictures.

\subsection{Fatigue crack propagation test}

The fatigue crack propagation test was carried out using an electric-hydraulic fatigue tester (made by Shimadzu Corp. Ltd.) with a capacity of $\pm 19.6 \mathrm{kN}$. The shape of the specimens were the same as those employed for a 1CT-type fatigue tester ${ }^{9)}$ compliant with ASTM standards and the sheet thickness of the specimens were $12.5 \mathrm{~mm}$ (Fig. 2). The test was conducted using a sinusoidal load control system with a load repetition frequency of $20 \mathrm{~Hz}$, and a gradually decreasing load system with $c=-0.08$ in the $K$-gradient at the stress ratio, $R=0.1$.

The same kind of method was used in the test environments mentioned in our previous paper; ${ }^{6)}$ namely, in the dry (Dry) atmospheric environment, in an environment with a relative humidity, $R H$, of $40 \pm 5 \%$, and that with an $R H$ of $80 \pm 5 \%$, each at room temperature. 
The lengths of the cracks on both sides were measured at a resolution of $0.01 \mathrm{~mm}$ using a movable-type reading microscope, and the average values were assumed to be the crack lengths. The crack propagation rate $\mathrm{d} a / \mathrm{d} N$ was calculated using the secant method, ${ }^{10}$ and was obtained using the load repetition number that is required for a crack to propagate by $0.5 \mathrm{~mm}$. We then conducted a comparative evaluation of the crack propagation properties of the samples after obtaining the $\mathrm{d} a / \mathrm{d} N$ and $\Delta K$ values. ${ }^{11,12)}$

Measurements for the crack closure that affects the fatigue crack propagation property were conducted using the unloading elastic compliance method. ${ }^{13)}$ A load cell was used to detect the applied load $(P)$, and a strain gauge attached to the test piece surface was used to detect the strain $(\varepsilon)$, then a computer was used to read and analyze the data. In this test, a closure diagram was created based on the computer calculations using both sets of data for $P$ and $\varepsilon$, to calculate the crack opening ratio $U$, which shows the degree to which the cracks have opened. Thereafter, we calculated the effective stress intensity factor range $\Delta K_{\text {eff }}$ by multiplying $\Delta K$ by $U . \Delta K_{\text {eff }}$ shows the stress extension coefficient range in which only the opened cracks propagate, excluding crack closures.

After the fatigue crack propagation test was completed, CT specimens were forcibly fractured with liquid nitrogen, to observe their fracture surface. The main factor for the crack closure phenomenon occurring in the low $\Delta K$ region has been attributed to a fretting oxide forming due to oxygen contact with the fractured surface. Next, backscattered electron images of the fractured surfaces for each material were taken in the vicinity of the crack closures. Then, an oxygen analysis was carried out on these fractured surfaces by performing an EPMA analysis to observe whether oxides had adhered to the portions at near $\Delta K_{\text {th }}$.

\section{Results and Discussion}

\subsection{Moisture effects on tensile strength properties}

Table 2 shows the mechanical properties for each of the materials obtained from the tensile test. Focusing on the intensities of the materials in the atmospheric environment at room temperature (Air) and in the water environment (Water), the PDI tensile strength was $955 \mathrm{MPa}$ in the Air environment, and $861 \mathrm{MPa}$ in the Water environment. As the ratio of ferrite increased, the intensity decreased and both the elongation rate and the reduction of area increased. The FDI specimen showed the highest values for both the elongation rate and the reduction of area. Next, with regard to the tensile strength, although the tensile strength was almost completely unaffected by the test environment for both FDI and FDPI.82, it decreased by approximately $10 \%$ for FDPI.55 and PDI in the Water environment in comparison with the results in the Air environment.

Next, we compared the state of the fractured surface between both the test environments to evaluate how the water embrittlement phenomenon affected the state of the fractured surface. Figure 3 shows the results from the fractured surface observations for each material obtained using a scanning electron microscope (SEM). In the Air environment, for FPDI.55 and PDI, fractured surfaces composed of both brittle
Table 2 Results of tensile test in four materials under air and water conditions.

\begin{tabular}{cccccccc}
\hline \multirow{2}{*}{ FDI } & & $\begin{array}{c}0.2 \% \text { Proof } \\
\text { stress } \\
\sigma_{0.2} / \mathrm{MPa}\end{array}$ & $\begin{array}{c}\text { Tensile } \\
\text { strength } \\
\sigma_{\mathrm{B}} / \mathrm{MPa}\end{array}$ & $\begin{array}{c}\text { Elongation } \\
\delta / \%\end{array}$ & $\begin{array}{c}\text { Reduction } \\
\text { of area } \\
\phi / \%\end{array}$ & $\begin{array}{c}\text { Young's } \\
\text { modulus } \\
E / \mathrm{GPa}\end{array}$ \\
\cline { 2 - 8 } & Wir & 325 & 448 & 28 & 23 & 164 \\
\hline \multirow{2}{*}{ FPDI.82 } & Water & - & 431 & 28 & 23 & - \\
\cline { 2 - 8 } & Air & 351 & 512 & 17 & 15 & 165 \\
\hline \multirow{2}{*}{ FPDI.55 } & Water & - & 506 & 19 & 14 & - \\
\cline { 2 - 8 } & Air & 423 & 621 & 6 & 3 & 153 \\
\hline \multirow{2}{*}{ PDI } & Water & - & 546 & 5 & 2 & - \\
\cline { 2 - 8 } & Air & 591 & 955 & 5 & 6 & 156 \\
\hline
\end{tabular}

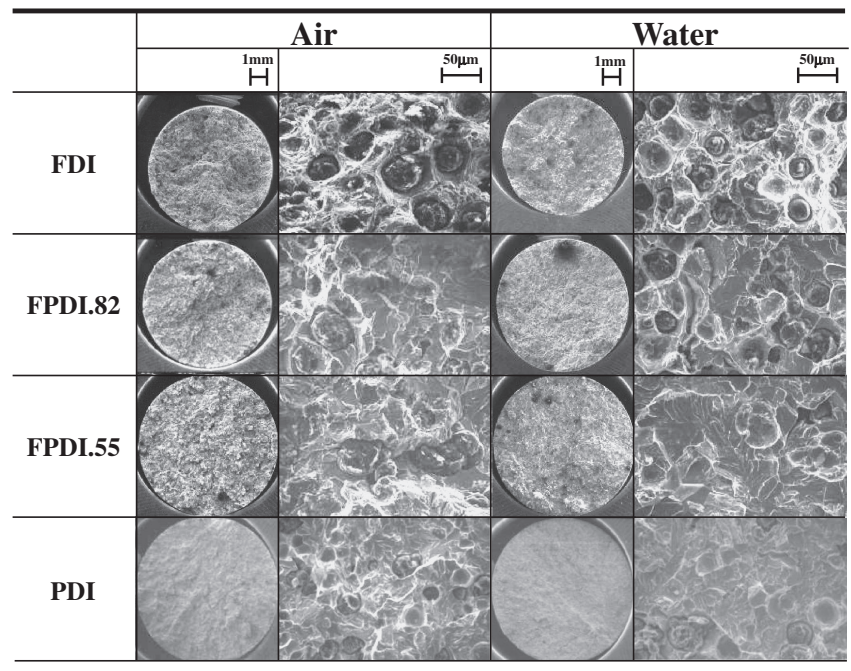

Fig. 3 Macro and microscopic fracture surface of tensile specimens under air and water conditions.

and ductile fracture surfaces were observed, and the ratio of ductile fracture surface increased as the ferrite ratio increased. Under the same conditions, for FPDI.82 and FDI, most of the ductile fracture surfaces were found. In contrast, in the Water environment, FPDI.55 and PDI both exhibited brittle fracture surfaces in an almost completely uniform manner. Figure 4 shows the relationship between the structure and the ratio of brittle fracture surfaces. In the figure, the plotted points represent the average measured values, and the upper and lower bars denote the maximum and minimum measured values. In the Air environment (at room temperature), the ratio of brittle fracture surfaces increased monotonically with a larger pearlite ratio. For FDI and FPDI.82, there was no significant difference found in the brittle fracture surface ratio between both the test environments. However, FPDI showed a significantly high increase of the brittle fracture surface ratio in the Water environment compared with that found in the Air environment, and the brittle fracture surface ratio for FPDI.55 in the Water environment was found to be almost identical to that found for PDI. Same as the test results reported by Shibuya et al., ${ }^{3)}$ it was determined that for the FPDI.55 and PDI samples, this was due to the effects brought about by the water embrittlement that is attributed to their pearlite structures. 


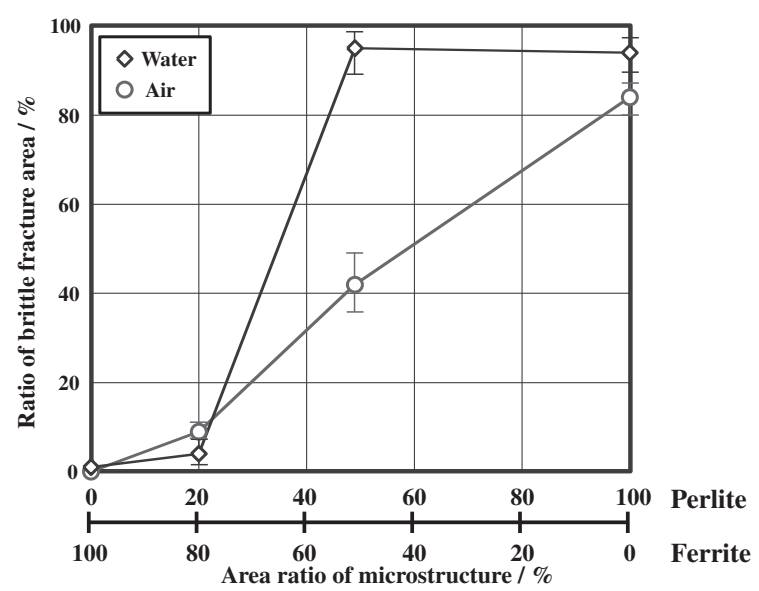

Fig. 4 Relationship between brittle fracture area ratio and microstructure.

\subsection{Moisture air effects on fatigue crack propagation properties}

The $\mathrm{d} a / \mathrm{d} N-\Delta K$ curves for each material are shown in Figs. 5(a)-(d). In the high $\Delta K$ region found in (a), (b), and (c) (FDI, FPDI.82, and FPDI.55), the crack propagation rate increased more in the humid environments $(\mathrm{RH}=40 \%$ and $80 \%$ ) that seen in the Dry environment, and the differences between these increased as the amount of pearlite component increased. However, there were no differences observed for PDI. Also, for all the materials, with the lower $\Delta K$, the crack propagation was brought to a sudden arrest in humid environments, whereas the cracks continued to propagate in the Dry environment. Focusing on the low $\Delta K$ region, the crack propagation rate varied widely between the humid and Dry environments for all the materials, and the threshold stress intensity factor range $\Delta K_{\text {th }}$ also showed higher values in the humid environments than in the Dry environment. The relationship between the values for humidity and the threshold stress intensity factor range $\Delta K_{\text {th }}$ for each material is shown in Fig. 6(a). With the higher humidity the $\Delta K_{\text {th }}$ values were found to be high in each of the materials. Figure 6(b) shows the relationship between different levels of humidity assuming that the $\Delta K_{\text {th }}$ value for each material be 1 (one) in the Dry environment. This relationship showed trends of improvement for each of the materials with the higher humidity. However, with the exception of the FDI samples, the same kind of trends were almost uniformly seen in each of the materials, and between the two humidity levels, the proportion of change was the same as each other because both types of samples contained pearlite structures in the matrix.

Fatigue crack propagation properties are known to be greatly affected by the crack closure. ${ }^{14)}$ Figures $7(a)-(d)$ show the $U-\Delta K$ curves for each of samples. $U$ decreased as (a)

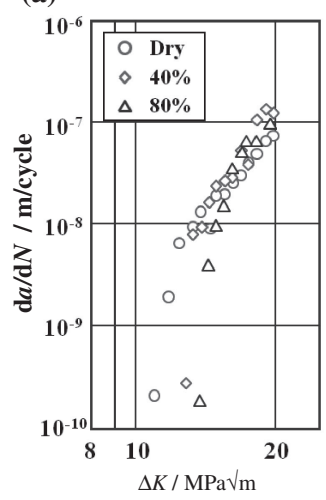

(b)

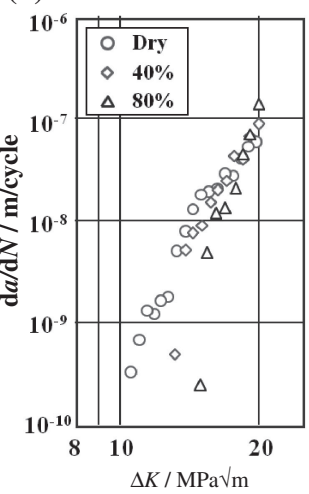

(c)

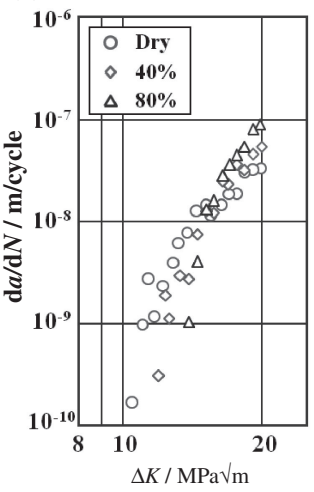

(d)

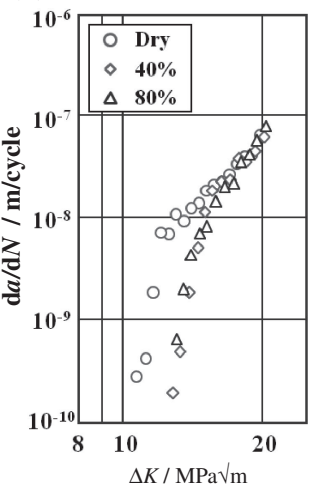

Fig. 5 Relationship between $\mathrm{d} a / \mathrm{d} N$ and $\Delta K$ in four materials under various humidity conditions; (a) FDI, (b) FPDI.55, (c) FPDI.82, (d) PDI.

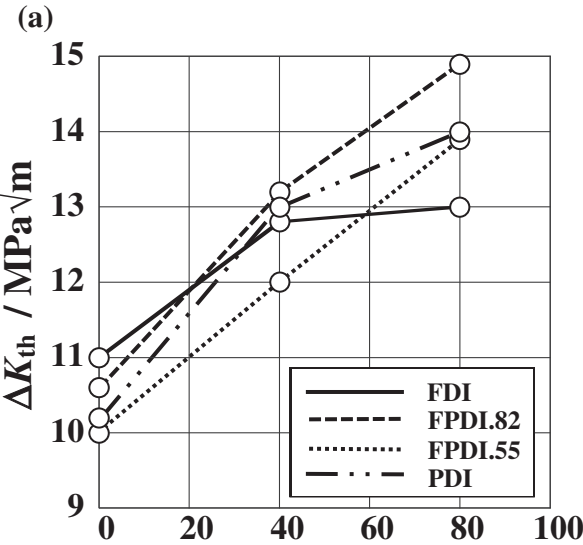

Humidity / \% (b)

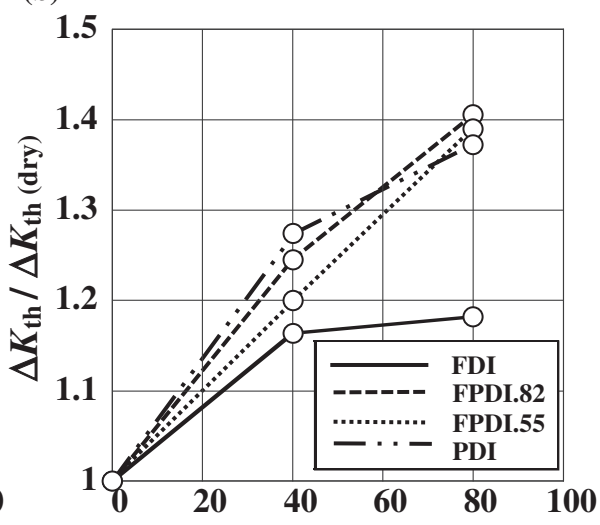

Humidity / \%

Fig. 6 Relationship between $\Delta K_{\text {th }}$ and Humidity in four materials; (a) $\Delta K_{\text {th }}$, (b) $\Delta K_{\text {th }} / \Delta K_{\text {th(Dry) }}$. 
(a)
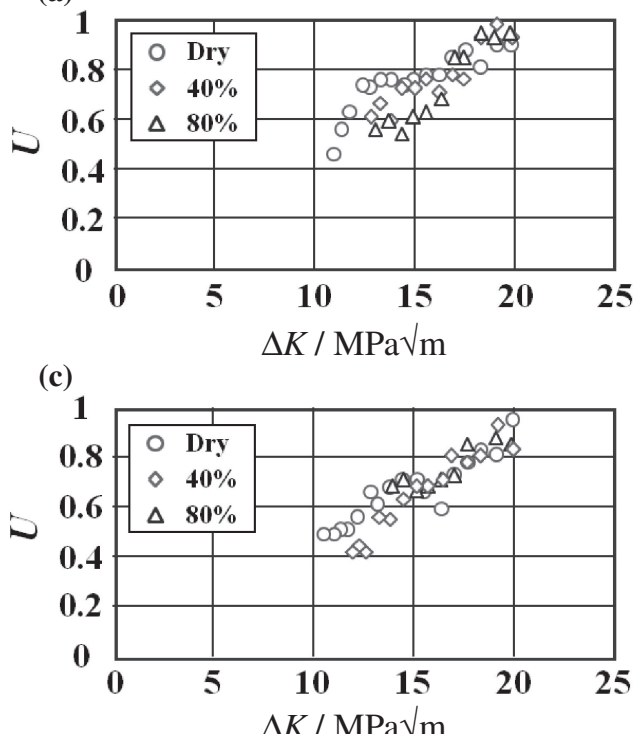

(b)

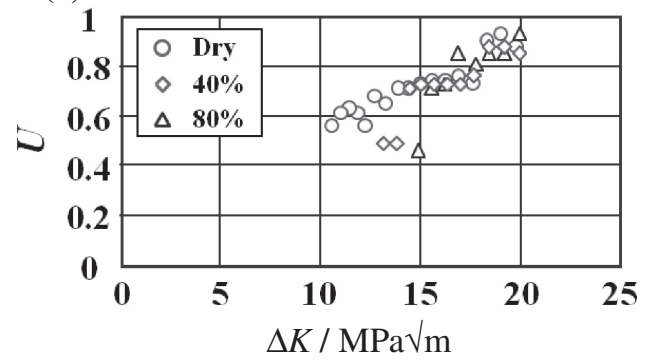

(d)

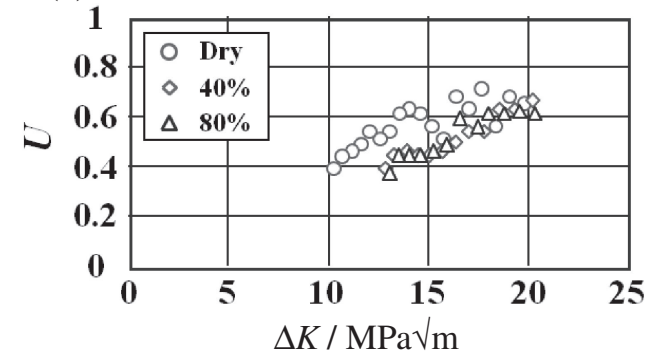

Fig. 7 Relationship between crack opening ratio, $U\left(=\Delta K_{\text {eff }} / \Delta K\right)$ and $\Delta K$ in four materials under various humidity conditions; (a) FDI, (b) FPDI.55, (c) FPDI.82, (d) PDI.

(a)

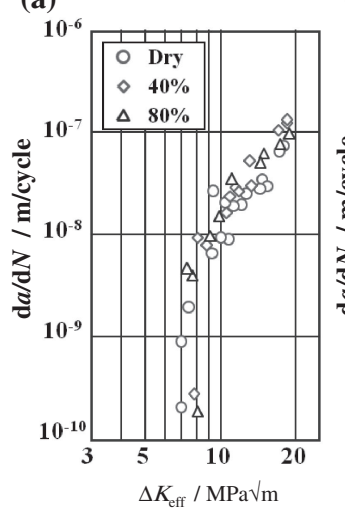

(b)

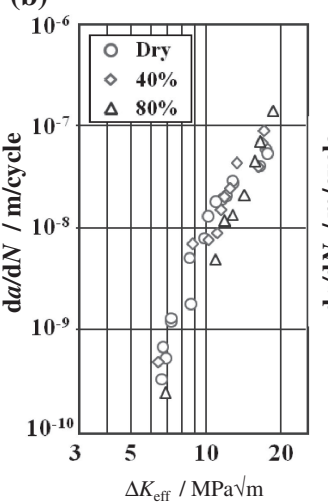

(c)

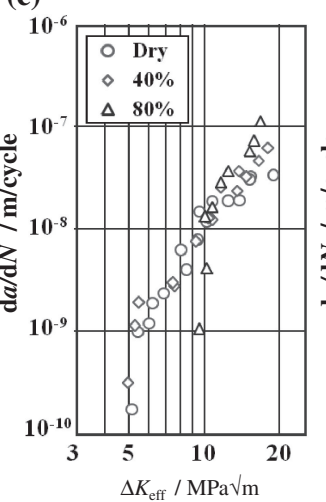

(d)

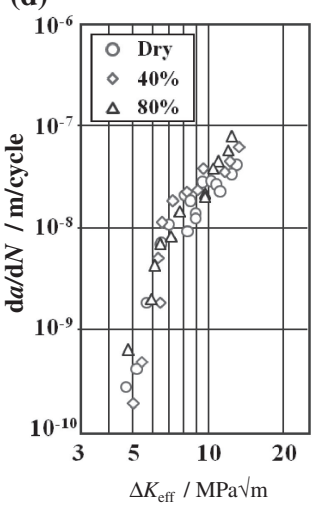

Fig. 8 Relationship between $\mathrm{d} a / \mathrm{d} N$ and $\Delta K_{\text {eff }}$ in four materials under various humidity conditions; (a) FDI, (b) FPDI.55, (c) FPDI.82, (d) PDI.

$\Delta K$ decreased, implying that crack closure occurred. Additionally, with the higher humidity, the decrease in $U$ also became larger, suggesting that with the higher humidity, the crack closure became more prominent.

To evaluate the fatigue crack propagation properties excluding any effects brought about by the crack closure, the $\mathrm{d} a / \mathrm{d} N-\Delta K_{\text {eff }}$ curves for the individual samples are shown in Figs. 8(a)-(d). Normally, the $\Delta K_{\text {eff }}$ is used to evaluate fatigue crack propagation properties exclusive of the effects of the crack closure. It is known that with these effects excluded from the evaluation, the $\mathrm{d} a / \mathrm{d} N-\Delta K_{\text {eff }}$ curves for the same type of samples will all converge into one line. The $\mathrm{d} a / \mathrm{d} N-\Delta K_{\text {eff }}$ curves for the FDI and the FPDI.82 specimens were not dependent on differences in the test environment and almost completely coincided with each other. The differences in the $\mathrm{d} a / \mathrm{d} N-\Delta K$ curves seen in Figs. 5(a)-(d) were determined to be mainly due to the crack closure. However, in the high $\Delta K$ region for FPDI.55, the crack propagation rate was still high in the moist environments in comparison to that found in the Dry environment. Addition- ally, in the high $\Delta K$ region for PDI, the crack propagation rate was high (although just slightly) in the moist environments in comparison to that found in the Dry environment. The difference in the crack propagation rate in the moist environments, as seen in the $\mathrm{d} a / \mathrm{d} N-\Delta K_{\text {eff }}$ curves, between FPDI.55 and PDI is thought to be attributed to a factor unrelated to the crack closure. As found in the tensile test results mentioned earlier, we determined this influential factor to be the water embrittlement phenomenon associated with the pearlite structure, and the acceleration phenomena with regard to the crack propagation rate brought about by the moist environments are also thought to be the effects of water embrittlement caused by pearlite. Usami et al. reported that phenomena similar to this were also observed in austempered spheroidal graphite cast iron, and that these were acceleration phenomena (for the crack propagation rate) similar to water embrittlement. ${ }^{5)}$ In addition to the results of the crack propagation test performed in this study, it is assumed that the effects (Fig. 8(c) and (d)) brought about by humidity seen in the high $\Delta K$ region for both the PDI and 


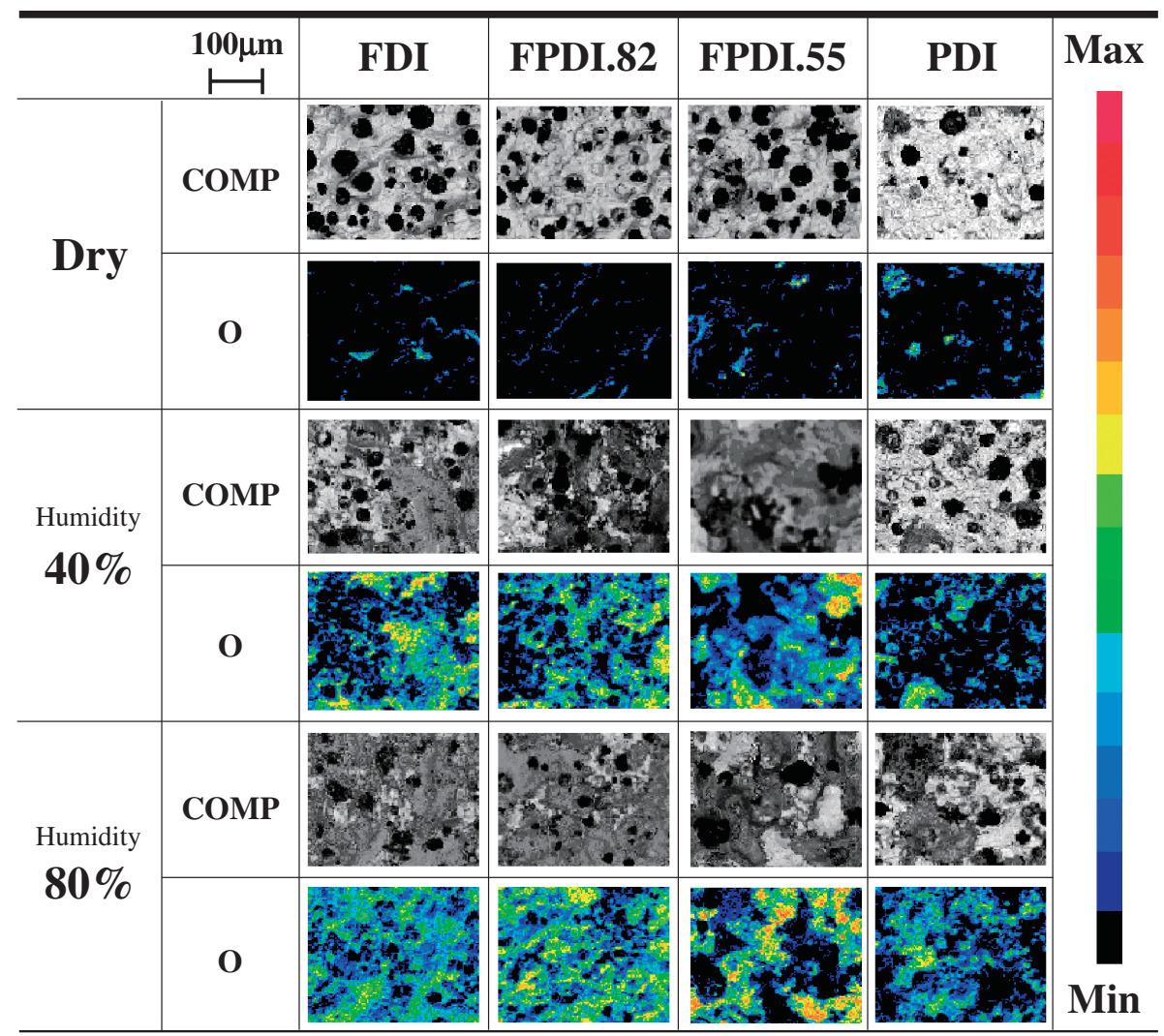

Fig. 9 Back scattered electron images and results of EPMA analysis (oxygen) at $\Delta K_{\text {th }}$ in four materials under various humidity conditions.

FPDI.55 samples be induced because the phenomenon similar to water embrittlement affected the pearlite phases contained within both sample materials. Focusing on the low $\Delta K$ region, with the exception of the results from the $80 \%$ humidity environment for the FPDI.55 samples, all of the other materials were found to coincide well with each other in the plot diagram. This is thought to be due to effects brought about by crack closure. However, the results from the $80 \%$ humidity environment for FPDI.55 still showed a high threshold value in comparison with those from other test environments. We can say that further detailed evaluation is needed as this cannot simply be explained in terms of phenomena similar to crack closure and water embrittlement.

Next, we evaluated the differences in the state of the fractured surface for each type of samples between both the humidity levels. Based on the characteristics of fractured surfaces, the crack closure can be classified into those due to oxides that have formed due to contact with the fractured surface (oxide-induced crack closure) ${ }^{15)}$ and those due to roughness of fractured surfaces (roughness-induced crack closure). ${ }^{16)}$ Figure 9 shows the back scattered electron images and the EPMA analysis results for the individual sample types. In the dry environment, there was very little oxygen detected on the fractured surfaces of any of the specimens. This implies that only a minimal amount of oxides formed on the fractured surfaces; therefore, we determined that oxide-induced crack closure did not occur. Next, in the $40 \%$ humidity environment, with the exception of the PDI samples, the remaining three types of samples all showed notable oxide. In the $80 \%$ humidity environment, notable oxide was found for all type of samples. Focusing on the results from the $40 \%$ humidity environment, there was a large amount of oxide on both the FDI and FPDI.82 specimens, both of which contained a large amount of ferrite, whereas less oxide was observed as the amount of pearlite increased. Therefore, this trend may be attributed to the increase in pearlite in the matrix. A significant degree of effects brought about by oxide-induced crack closure was determined to have occurred in response to increases in humidity. Additionally, since oxides increasingly formed with larger amounts of ferrite, the oxide-induced crack closure was determined to have more prominently occurred with higher ratios of ferrite.

From the results above, in high $\Delta K$ region for the PDI and FPDI specimens, the crack propagation rate acceleration phenomena are thought to be related to water embrittlement in pearlite structures within the matrix. Additionally, the differences in the crack propagation properties between different types of specimen in the low $\Delta K$ region were thought to be due to the effects brought about by oxideinduced crack closure. Oxides, which mainly formed in the ferrite phase within the matrix, were found more prominently with higher ratios of ferrite.

\section{Conclusions}

Four types of spheroidal graphite cast iron specimen (FDI, FPDI.82, FPDI.55, PDI) with differing ferrite-to-pearlite composition ratios were used in performing tensile tests and fatigue crack propagation tests to evaluate how atmospheric moisture affects their mechanical properties. The results are summarized in the following points. 
(1) The tensile strength for the FDI and FPDI.82 specimens remained almost completely unaffected by water embrittlement, whereas PDI and FPDI.55, which contained high ratios of pearlite, were affected by water embrittlement, causing a decrease in tensile strength.

(2) The brittle fracture surface fraction increased in the matrix with an increase in pearlite, and the samples showed trends of being affected by water embrittlement.

(3) All types of samples displayed high $\Delta K_{\text {th }}$ values in the moist environments $(R H=40,80 \%)$ in comparison to those seen in the Dry environment due to the effects brought about by atmospheric moisture.

(4) The crack closure was found to have occurred in all types of samples, which was prominently seen in the moist environments $(R H=40,80 \%)$.

(5) In low $\Delta K_{\text {eff }}$ region excluding the effects brought about by crack closure, with the exception of the results from the $80 \%$ humidity environment for FPDI.55, all of the samples were found to have coincided well with each other in the plot diagram. This suggests that this trend may be due to effects brought about by oxide-induced crack closure attributed to the ferrite phase within the matrix.

(6) In the high $\Delta K_{\text {eff }}$ region for FPDI and PDI, the data did not coincide with each other even when the effects brought about by crack closure were taken into consideration, suggesting that acceleration phenomena had occurred due to the effects of the moist environments. This implies that phenomena similar to water embrittlement in the pearlite contained within the matrix may have contributed to fatigue crack propagation as well.

\section{Acknowledgments}

This study is composed partially of activities that were able to be carried out thanks to the Young Researchers Grant sponsored by the Japan Foundry Engineering Society, for which we would like to express our gratitude and appreciation to all persons involved.

\section{REFERENCES}

1) S. Yamada and S. Tsukahara: The Characteristic of Mechanical Properties and Heat Treatment in Cast Irons, (AGNE Gijyutsu Center, 2004) p. 2.

2) T. Ogawa, K. Shamoto and K. Tokaji: J. Soc. Mat. Sci. Jpn. 42 (1993) 183-188.

3) S. Shibuya and Y. Tanaka: J. JFS 70 (1998) 115-120.

4) Q. Cai and Y. Tanaka: J. JFS 71 (1999) 411-417.

5) H. Usami, Y. Sugiyama, N. Shiraki, M. Funamoto and Y. Kimura: J. Soc. Mat. Sci. Jpn. 53 (2004) 207-212.

6) N. Shiraki and Y. Atsumi: J. JFS 79 (2007) 83-89.

7) JIS G 5502: Spheroidal Graphite Iron Castings, (2007).

8) JIS Z 2241: Metallic Materials-Tensile Testing-Method of Test at Room Temperature, (2011).

9) ASTM E647-05:Standard Test Method for Measurement of Fatigue Crack Growth Rates, (2006).

10) T. Kunio, H. Nakazawa, K. Hayashi and H. Okamura: The Testing Method of Fracture Mechanics, (Asakura Publishing Co. Ltd., 1984) p. 166.

11) J. E. Srawley: Int. J. Frac. Mech. 12 (1976) 475-476.

12) J. E. Newman: ASTM STP 560 (1974) 105-123.

13) M. Jyono and T. Sou: The Fatigue Crack-Crack Closure and Estimation of Propagation Rate-, (Osaka Univ. Press, 2005) p. 37.

14) H. Kobayashi, T. Ogawa, H. Nakamura and H. Nakazawa: Trans. JSME Ser. A 50 (1984) 309-319.

15) K. Minakawa and A. J. McEvily: Scr. Metall. 15 (1981) 633-636.

16) A. T. Q. Stewart: Eng. Fract. Mech. 13 (1980) 463-478. 